\title{
An unusual cause of 'tree-in-bud' appearance in CT-chest during COVID-19 pandemic
}

\author{
Ankur Sharma1, Balakrishnan Narayanan², Nilay Pal'², Sunny Taye ${ }^{2}$ \\ ${ }^{1}$ Department of Trauma and Emergency (Anesthesiology); ${ }^{2}$ Department of Anesthesiology and Critical Care, All India \\ Institute of Medical Sciences, Jodhpur, India
}

\begin{abstract}
'Tree-in-bud' (TIB) appearance in computed tomography (CT) chest is most commonly a manifestation of infection. We here describe an unusual cause of TIB during the COVID-19 pandemic. A young male patient who had a history of fever, cough, and respiratory distress presented in the emergency department. As these symptoms matched with coronavirus infection, the COVID-19 test was done, which was found negative. He was then moved to the intensive care unit where he developed severe acute respiratory distress syndrome and was put on mechanical ventilation.

Further workup did not reveal any source of infection, as all his cultures were negative, but his CT chest showed a tree-in-bud appearance. After obtaining a detailed history from his friends, the patient was found a chronic abuser of inhaled cocaine and treated with intravenous steroids. Subsequently, he was weaned from the ventilator and discharged from the intensive care unit after becoming asymptomatic.
\end{abstract}

Correspondence: Ankur Sharma, Department of Trauma and Emergency (Anesthesiology), All India Institute of Medical Sciences, 58 Subhash Nagar -2, Jodhpur, 342008, India.

E-mail: ankuranaesthesia@gmail.com

Key words: Computed tomography; tree-in-bud; cocaine; unusual.

Conflict of interest: The authors declare that they have no competing interests, and all authors confirm accuracy.

Contributions: All authors contributed equally to this manuscript, have read and approved the final version of the manuscript and agreed to be accountable for all aspects of the work.

Patient consent for publication: Written informed consent for publication was obtained from the patient.

Received for publication: 21 June 2020.

Accepted for publication: 3 August 2020

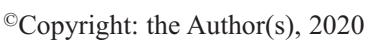

Licensee PAGEPress, Italy

Monaldi Archives for Chest Disease 2020; 90:1466

doi: 10.4081/monaldi.2020.1466

This article is distributed under the terms of the Creative Commons Attribution Noncommercial License (by-nc 4.0) which permits any noncommercial use, distribution, and reproduction in any medium, provided the original author(s) and source are credited.

\section{Introduction}

The 'tree-in-bud' (TIB) pattern is commonly seen in multiple respiratory disorders in computed tomography (CT) chest scans. Recognizing this crucial radiological sign is essential for a proper diagnosis. This pattern is shown when remote airways are clogged with pus or fluid with peribronchial inflammation [1]. These airways are well delineated by CT scanning, which gives a tree-like pattern. A bud-like pattern can be seen when respiratory bronchioles and alveolar ducts are swollen. That is why it is named 'treein-bud.' It had initially been identified in Mycobacterial Tuberculosis endobronchial spread. It was further recognized in several conditions such as aspiration, atypical mycobacterial infections, pneumonia, low-grade adenocarcinoma, immune deficiencies, etc. Recognition of this CT sign's pathophysiology and etiology is crucial for making a proper and prompt diagnosis [1].

Here, we report a rare case of 'tree-in-bud' appearance in CT chest in a patient presented during the COVID-19 pandemic and was later diagnosed as cocaine-induced lung injury (crack lung).

\section{Case Report}

A 25-year-old male patient presented in the emergency department with complaints of fever, difficulty in breathing at rest, and cough with expectoration of blood for two days. The patient was a smoker for the past five years with no history of contact with tuberculous patients. On examination, the patient was irritable with respiratory rate $40 / \mathrm{min}$, heart rate: 130/min, BP: 155/90 $\mathrm{mm} \mathrm{Hg}$, and oxygen saturation $90 \%$ on room air. Auscultation revealed bilateral coarse crepitations in the middle and lower zones. Since he presented at the time of COVID-19 pandemic, reverse transcription-polymerase chain reaction (RT-PCR) was done, which was negative. Chest X-ray of the patient showed bilateral diffuse, opacities in the middle and lower zone (Figure 1). Electrocardiography and 2D echo showed a normal result.

Initial blood counts, including the differential count, coagulation profile, liver function test, and renal function tests were in normal limits. Laboratory studies showed a white blood count of $10.2 \times 10^{3} / \mu 1$ with serum eosinophils $5.4 \%$ (ref (2-8\%), absolute eosinophil count: $0.55 \times 10^{3}$ cells/ $\mu 1$ ). Because of the increase in oxygen requirement and respiratory acidosis, the patient was intubated and mechanically ventilated as per lung protection strategy (tidal volume $6 \mathrm{ml} / \mathrm{kg}$, plateau pressure $<30 \mathrm{~cm} \mathrm{H}_{2} \mathrm{O}$ ). His sputum for acid-fast bacilli and cultures were sterile. A bronchoscopy was performed with bronchoalveolar lavage (BAL) to investigate possible infection (mycosis, SARS-COV-2, bacteria, viruses, etc.). 
But there was no growth or any microorganism seen. All the other cultures (blood, urine and tracheal) and microscopic investigations were also sterile. Serial procalcitonin values were also within the normal range. His condition was not improving even after the administration of intravenous broad-spectrum antibiotics. Arterial blood gas (ABG) showed a picture of severe acute respiratory distress syndrome (ARDS) with an arterial $\mathrm{PaO}_{2}$ (partial pressure of oxygen) $/ \mathrm{FIO}_{2}$ (the fraction of inspired oxygen) ratio of $80 \mathrm{~mm} \mathrm{Hg}$. The contrast-enhanced CT of the chest revealed bilateral lower lobe consolidation with numerous 'tree-in-bud' nodules (Figure 2) in both lungs, which usually suggest active infective etiology. But in the present case, we did not find any source of infection. On discussion with his friends, we found that the patient used to smoke crack cocaine occasionally. He inhaled cocaine $48 \mathrm{~h}$ before presenting to these symptoms.

Because of the crack lung, intravenous methylprednisolone 50 mg every six hourly was administered. After one day of starting methylprednisolone, the patient's oxygenation and respiratory acidosis improved. He improved clinically, and the chest became clear. Subsequently, the patient's trachea was extubated on day two after starting steroids, which was tapered gradually. At the time of extubation, his chest X-ray was normal. After extubation, he admitted that he had smoked crack cocaine.

\section{Discussion}

'Tree-in-bud' appearance in CT chest is most commonly a manifestation of infection [2]. Miller et al. in their study on 166 cases with TIB opacities found its causes as respiratory infections $(72 \%)$ with mycobacteria $(39 \%)$, bacteria $(27 \%)$, viruses $(3 \%)$, or multiple organisms (4\%) and aspiration (25\%) [1]. But in our patient, we found no evidence of infection. But later, he was diagnosed with a case of non-infective pathology of inhaled crack cocaine.

Cocaine is an alkaloid that is naturally available and extracted from the leaf of the Erythroxylon coca plant. It is one of the commonly abused drugs in the United States, with around 1.5 million active drug users [3]. There are four forms of cocaine available: hydrochloride salt, 'freebase,' crack, and 'bazuco.' The toxic effects of cocaine depend on the route, dose, and frequency of administration and particulate size [4]. Crack is the most effective and addictive type of cocaine, and because of its euphoric effects, smoking is the preferred method for drug users. Smoke cocaine gets absorbed across the mucosal membranes and lungs. Nasal insufflation of cocaine has a strong toxic impact on the lungs and causes a wide range of complications, including interstitial pneumonitis, fibrosis, pulmonary hypertension, and alveolar hemorrhage [5]. Many patients present with pulmonary involvement, and the differential diagnosis includes acute and chronic eosinophilic pneumonia, Churg-Strauss granulomatosis, viral pneumonia, parasitic eosinophilic pneumonia, drug-induced eosinophilic pneumonia [6]. Patients with cocaine-induced eosinophilic pneumonitis may have pulmonary eosinophilia in BAL. Bronchial eosinophils count was not reported in our case. Peripheral eosinophilia may be present in $40 \%$ of these patients [6]. In the present case, the serum eosinophils count was within a normal range.

The common presenting symptoms of crack cocaine abuse are shortness of breath, fever, and hemoptysis. All these findings are mostly present in infective pathology. In the absence of any suspicion of infection, cocaine-induced lung injury (crack lung) can be considered as a differential diagnosis in these patients. The exact pathogenesis of hemoptysis in crack cocaine abuse is unclear. Current theories include vasoconstriction-mediated hypoxic alveolar epithelial or capillary endothelial cell damage and direct cyto-

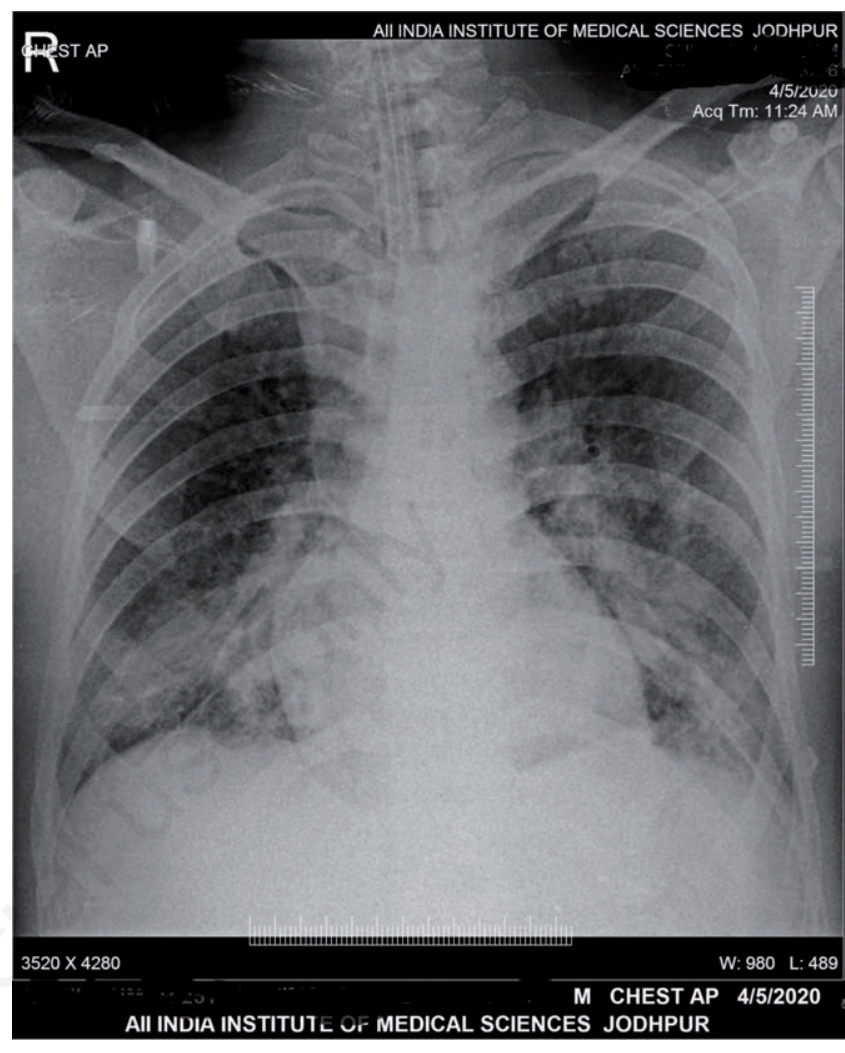

Figure 1. Chest X-ray of the patient showed acute respiratory distress syndrome (bilateral diffuse, opacities in the middle and lower zone).

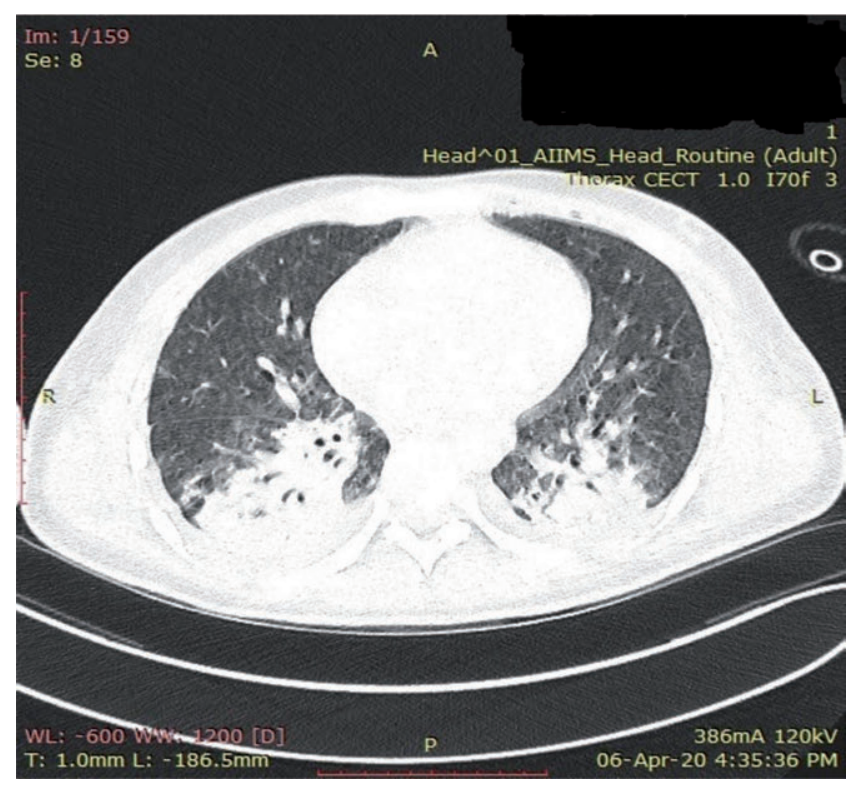

Figure 2. Computed tomography of the chest in the pulmonary window revealed centrilobular nodules with 'tree-in-bud' appearance. 
toxic effects of substances ingested with cocaine [7]. In the case presented above, the differential diagnosis of the presenting complaints includes aspiration pneumonia, congestive cardiac failure, viral pneumonitis, and bacterial pneumonitis, but all these differential diagnoses have been ruled out in our case [8]. Rapid improvement after the administration of methylprednisolone suggests that steroids can be used to manage cocaine-induced lung injury. We administered broad-spectrum antibiotics for the infection, but ARDS did not resolve.

\section{Conclusions}

Although the 'tree-in-bud' appearance in CT chest is most commonly a diagnosis of an infective cause, it can rarely be found in a non-infective pathology like in the present case of cocaineinduced lung injury. One should use his clinical judgment and obtain a detailed history to reach an exact diagnosis. If the cause is uncertain, before confirming the diagnosis of cocaine-induced lung injury, all the other differential diagnoses should be ruled out.

Rapid improvement following the administration of steroids, as in this case, indicates that it can be used in the management of cocaine-induced lung injury.

\section{References}

1. Miller WT, Panosian JS.Causes and imaging patterns of treein-bud opacities. Chest 2013;144:1883-92.

2. Shimon G, Yonit WW, Gabriel I, et al. The "tree-in-bud" pattern on chest CT: Radiologic and microbiologic correlation. Lung 2015;193:823-9.

3. Substance Abuse and Mental Health Services Administration. Results from the 2013 National Survey on Drug Use and Health: Summary of National Findings, NSDUH Series H-48, HHS Publication No. (SMA) 14-4863. Rockville: Substance Abuse and Mental Health Services Administration; 2014.

4. Ryan SA. Cocaine use in adolescents and young adults. Pediatr Clin North Am 2019;66:1135-47.

5. Pianca TG, Rohde LA, Rosa RL, et al. Cocaine use in adolescents: Clinical characteristics and predictors of early initiation. J Clin Psychiatry 2016;77:e1205-10.

6. Restrepo CS, Carrillo JA, Martinez S, et al. Pulmonary complications from cocaine and cocaine-based substances: imaging manifestations. Radiographics 2007;27:941-56.

7. Reyes F, Vaitkus V, Al-Ajam M. A case of cocaine-induced eosinophilic pneumonia: Case report and review of the literature. Respir Med Case Rep 2018;23:98-102.

8. Mégarbane B, Chevillard L. The large spectrum of pulmonary complications following illicit drug use: features and mechanisms. Chem Biol Interact 2013;206:444-51. 